\title{
Three-Dimensional Detection of Pulmonary Nodules in Chest CT Images
}

\author{
Aliaa A. A. Youssif \\ Computer Science Department \\ Helwan University \\ Cairo, Egypt \\ E-mail: aliaay@helwan.edu.eg \\ Shereen A. Hussein \\ Computer Science Department \\ Helwan University \\ Cairo, Egypt \\ E-mail: eng_shereen@hotmail.com
}

\author{
Ahmed S. Ibrahim \\ Radiodiagnosis Department \\ Ain Shams University \\ Cairo, Egypt \\ E-mail: asibrahima@gmail.com
}

Received: July 26, 2011

Accepted: August 16, 2011

doi:10.5539/cis.v4n5p2

\begin{abstract}
Small pulmonary nodules are radiologic findings that represent an important challenge in diagnosis systems. While these nodules are the major indicator for lung cancer and metastasis, their properties like size and location play an important role in classifying the benign one from the malignant. Estimating the growth rate of the nodule size states the degree of malignancy.

This paper presents a computer-aided diagnosis (CAD) system to detect small-size pulmonary nodules from the chest computed tomography (CT) images through two dimensional (2-D) and three-dimensional (3-D) methods. Also, a computed volumetric growth is a promising way to distinguish malignant from nonmalignant pulmonary nodules. It was applied to lung nodules ( 2 to $7 \mathrm{~mm}$ in diameter) and achieved sensitivity $94.6 \%$ with an average; it is expected to aid radiologists in the detection of small nodules on thin-section multi-detector row CT images.
\end{abstract}

Keywords: Computer-aided diagnosis (CAD), Computed tomography (CT), Morphologic operations, Co-occurrence matrix, 3D region growing, Growth rate

\section{Introduction}

Pulmonary nodules are important finding in Computed Tomography (Fischbach F, 2003) (CT) which helps in the detection of lung cancer (American Cancer Society, 2003) (R. T. Greenlee, et al, 2001) at earlier and more curable stages. Depending only on the radiologist view to detect the nodules may lead to false results which increase the death percentage.

With the fast advancement of MDCT, there is an urgent need to develop computer aided tools to detect the largest possible number of different size nodules and to measure their features (size, location, compactness and elongation). The 3D volume estimation allows follow-up of the growth rate for nodules with labeling as benign or malignant to determine the appropriate therapy.

One of the best predictors of nodule malignancy is growth rate or doubling time (William J. Kostis, et al, 2003) (J. P. Ko \& M. Betke, 2001) (Henschke, et al, 2004). As, nodule size is also highly correlated with malignancy. 
Significantly larger nodules ( $>3 \mathrm{~cm}$ in diameter) are more likely to represent lung cancer (William J. Kostis, et al, 2003). Characterization of nodules as early as possible, i.e., when they are still small in size is the basic element for accurate diagnosis.

\section{Previous Work}

Generally speaking, there are two possible philosophies for designing a CAD system:

1- The first is based on the determination (by means of thresholding and segmentation algorithms) of the parenchymal volume and the search of the nodules only inside that volume.

2- The second is based on the search of the nodules in the overall CT-scanned volume and the determination of the position of the nodule with respect to the parenchyma.

Each philosophy has its advantages and disadvantages but the basic requirement for any good performing CAD System (Gurcan MN, et al, 2002) (Reeves AP \& Kostis WJ, 2000) (Reeves AP \& Kostis WJ, 2000) (Armato SG, et al, 2001) is to have an accurate automated selector of nodule candidates (exactly defined volume) to reduce the worse sensitivity and specificity possibility. Other aspects should be considered in the detection of nodules is their position and shape as there are two classes: - an "internal nodule" which is located inside the nodule (quite spherical shape) and "pleural nodules" which is connected somehow to the pleural surface (irregular shape). A number of methods and systems for automated nodule detection are developed over the years (D.-Y. Kim, et al, 2003) (Brown MS, et al, 2003) (Lee Y, et al, 2001), some are focused on the "density" (considering the fact that lung nodules have relatively higher densities than those of lung parenchyma) while others are focused on "model" (considering some features like compactness, elongation and size).

Two-dimensional measures are used in proposing nodule candidates in detecting algorithms and estimating the malignancy degree of the identified nodules. Giger et al. (M. L. Giger, et al, 1994) reported the use of perimeter, area, compactness, and circularity features in 2-D automated nodule detection. Toshioka et al. (S. Toshioka, 1997) added mean density and variation measures to improve the detection performance. McNitt-Gray et al. (M. F. McNitt-Gray, et al, 1999) used also texture measures to the previous mentioned features. Other 2-D methods for nodule segmentation and growth rate analysis have also been described (J. P. Ko \& M. Betke, 2001) (M. F. McNitt-Gray, et al, 2001).

Three-dimensional (3-D) measures of nodule volume, shape and location have been described (D. F. Yankelevitz, et al, 2000) (William J. Kostis, et al, 2003). Brown et al. Described automated lung region segmentation by fuzzy matching (M. S. Brown, 2001). Ko and Betke, identified the nodule location and evaluated it by tracing volume change (decrease, stable, increase) (J. P. Ko \& M. Betke, 2001).

\section{Pulmonary Nodules Detection Proposed System}

Materials and methods to produce the system are explained as follows.

\subsection{CAD Algorithm}

This CAD algorithm was designed and organized to use 3D algorithms that take advantage of thin-section volumetric CT data, it has combined both 3D and 2D morphologic operations in the segmentation, detection, and classification of pulmonary nodules to get more efficiency and accuracy based on CT volumetric data acquired from multi-detector row $\mathrm{CT}$ which have four main modules (2D preprocessing, 3D preprocessing, Detection and classification) as illustrated in flowchar shown in Figure 1.

\subsection{Automated Extraction of the lungs}

Segmentation for the thorax and lung region was based on a thresholding method in each section. The threshold was determined by analyzing the 2D region histogram, which showed distinct groups of pixels belonging to the thorax and background air (Russ JC, 2002) (J. P. Ko \& M. Betke, 2001). The thoracic region was segmented from the thresholded binary image. Background pixels representing air outside the thorax were clipped, and the morphologic operations of erosion and dilation were applied to eliminate the scattered background. The boundary detection processes were repeated in the segmented thorax region to segment the lung region.

The lung boundary detected with the gray-level thresholding technique often does not include juxtapleural nodules because these nodules are contiguous with the body wall and are thus segmented as a part of the body wall instead of the lung region. In addition, central pulmonary vessels with any attached vascular nodules may be excluded from the segmented lung region. A morphologic operation was performed to correct such segmentation "errors" in the lung boundary. Circular "closing" filters of variable diameters were applied iteratively to the segmented lung region to capture the juxtapleural nodules and to include central pulmonary vessels. The closing filter consists of a dilation followed by erosion morphologic operations and is used to fill in holes and small gaps. 
The segmentation process of the lung region, including boundary revision, is illustrated in Figure 2. The final segmented lung region contains three types (isolated, juxtapleural, and vascular) of lung nodules, blood vessels, pulmonary parenchyma, airway, and other structures.

\subsection{Density Computation}

Sometimes, Hounsfield unit is an indicator for the calcified or non-calcified nodules (S. Antani, 2004). In the image processing steps, grey level values rather than Hounsfield units (HU) are utilized. Figure 3 shows the range for $\mathrm{HU}$ values.

$$
\mathrm{HU}=\text { grey level }-1024 \text { (Binsheng Zhao, et al, 2003) }
$$

Equation 1. Hounsfield unit calculation based on the gray level value

\section{$3.43 D$ volume data generation \& growing}

The 2D segmented lung regions were stacked to generate a 3D data set for lung volume (D. F. Yankelevitz, et al, 2000) (M. F. McNitt-Gray, et al, 2001), and a region-growing technique with 18-connectivity was applied to the voxels to group contiguous structures in three dimensions. The volume of each group was computed by counting the number of connected pixels and converting its dimension to cubic millimeters. Grouping and labeling processes were applied to the connected soft-tissue structures (nodule candidates and vessels) in the segmented lung regions to generate a 3D data set (Figure 4b). In each lung, the largest connected structure corresponded to the pulmonary vessel tree. The nodules attached to the vessels, vascular nodules - were also included in this vessel group (Figure 4c). The remaining soft-tissue structures were labeled and stored as the non-vessel group, which contains isolated and juxtapleural nodules.

\subsection{Detection of nodule candidates}

There are two types of nodule candidates; each one has a different method for its detection.

\subsubsection{Juxtapleural nodule candidates}

Isolated and juxtapleural nodule candidates were first detected from the non-vessel group by excluding non-nodule soft-tissue structures that did not satisfy predetermined nodule size and geometric and shape constraints (D.-Y. Kim, et al, 2003) (Brown MS, et al, 2003) (Lee Y, et al, 2001).

First, the Nodule size with an upper limit $3 \mathrm{~cm}$ on diameter or volume $14.14 \mathrm{~cm}^{3}\left(43 \pi[1.5]^{3}\right)$ and lower limit $3 \mathrm{~mm}$ or $14.14 \mathrm{~mm}^{3}$ in volume thus, the candidate with size not in the predefined range was considered to be non-nodule (background noise).

Second, the compactness of each nodule candidate was computed as the ratio of its volume to the volume of the smallest 3D box that encloses the candidate structure. As the nodules are compact and spherical, the candidate with compactness values less than 0.5 or greater than 1.5 was considered to be non-nodule.

Third, elongation factor was computed for each candidate by using the ratio of the maximum to the minimum eigenvalues that were calculated from the voxel coordinates of the candidate structure. The elongation factor becomes close to 1 for a relatively round or spherical structure.

While a candidate with an elongation factor of greater than three was considered to be a non-nodule. The remaining nodule candidates that were not excluded according to size, compactness, and elongation criteria from the non-vessel group were subsequently classified as nodules.

\subsubsection{Vascular nodule candidates}

Detection of vascular nodules (D.-Y. Kim, et al, 2003) (Brown MS, et al, 2003) (Lee Y, et al, 2001), however, is more difficult than that of isolated or juxtapleural nodules because vascular nodules are attached to the pulmonary vessels. Vascular nodules are distinguished morphologically from the vessels because they are typically spherical in shape, while the vessels are elongated. Direct application of shape criteria, such as compactness or elongation factor, is ineffective for the identification of nodule candidates without disassociating them from the attached vessels, so a 3D multilevel morphologic matching method was used to identify and extract vascular nodule candidates from the vessel group. These filters were spherical in shape, and four different sizes of the filters $(3,6,9$, and $12 \mathrm{~mm}$ in diameter) were used to identify nodule candidates ranging from 3 to $30 \mathrm{~mm}$. Each filter was particularly sensitive in the detection of nodule candidates whose diameters were close to that of the corresponding filter.

The morphologic filters were convolved with the 3D data of the vessel group to compute correlation factor. The correlation between 3D data and morphologic filters can be expressed in terms of the fast Fourier transform method. After the correlation was computed, vascular nodule candidates were selected by performing 
thresholding of the correlation values. The threshold value was determined empirically at $70 \%$. The use of lower threshold values, as with the use of an increasing number of morphologic filters, increased the sensitivity of detecting nodule candidates but at the price of increasing the computation time and the number of false-positive candidates. After the multilevel matching process, 3D region growing and labeling was applied to the nodule candidates. The 3D shape and geometric features were computed for each candidate. Candidates classified (Way TW, et al, 2006) (Beigelman-Aubry C, et al, 2007) (Ahn MI, et al, 2010) as non-nodules were eliminated by means of the rule based scheme, as described in detecting the isolated and juxtapleural nodules, and the remaining candidates were flagged as nodules.

\subsection{Classification the detected nodules (Benign/Malignant)}

Differentiating between benign and malignant nodules helps in treatment decisions especially at early stages. Neural networks (Y. Matsuki, et al, 2002) are touted as predictive systems that are useful in medical diagnosis. They have many desirable properties that make them ideally suited to this task as they are simple to develop, they learn by examples and they deal with ambiguity or missing data.

A three-layer feed-forward neural network used as a tool for classification between benign and malignant nodules based on the extracted features from some patient images co-occurrence matrices, and then determines the query nodule type for the patient.

\subsubsection{Co-occurrence Matrices}

Statistical methods (T. Andrysiak \& M. Choras, 2005) (H. Mller, et al, 2004) (Qian J, et al, 2002) such as Haralick co-occurrence (A. Materka \& M. Strzelecki, 1998) (Michael Lam, et al, 2010) matrices generally focus on the distributions and relationships of the gray levels in an image. The general idea of a co-occurrence matrix is to represent an image's texture features by counting pixel intensity pairs, using a matrix to keep track of all the pixel-pair counts. Our method calculates a separate co-occurrence matrix for each direction $\left(0^{\circ}, 45^{\circ}, 90^{\circ}\right.$ and $135^{\circ}$ ) and displacement (1, 2, 3 and 4 pixels). After the co-occurrence matrices are formed, Haralick features are calculated from the matrix data. Since there are four directions, four displacements and eleven features, the result is a $4 \times 4 \times 11$ matrix, which is averaged by distance. The minimum values by direction are then stored as eleven elements in the feature space. These elements can then be combined to form feature vectors of varying lengths. Since there are eleven features, there are

$$
\mathrm{N}=\sum_{\boldsymbol{d}_{k=1}}^{j} \mathrm{j} ! / \mathrm{k} !(\mathrm{j}-\mathrm{k} !)
$$

Equation 2. No. of features combinations where $\mathrm{j}=11$ (Haralick features) and $\mathrm{N}=2047$ unique vectors

To determine which of these vectors were best for our data set, we wrote a routine to perform a simulated query for each image in the database and calculate the mean precision and recall.

\subsection{Evaluating Pulmonary Nodules}

After detecting the nodule, growth rate and doubling time (H. Mller, et al, 2004) (Qian J, et al, 2002) (William J. Kostis, et al, 2003) (J. P. Ko \& M. Betke, 2001) must be determined to evaluate the malignancy level (Henschke, et al, 2004) (Libby, et al, 2004) which lead to the appropriate medication (MacMahon H, et al, 2005) (Park EA, et al, 2009) (Tao C, et al, 2009) as shown in (Figure 5).

\section{Experimental Work}

The patient database consisted of diagnostic thoracic CT scans from 21 consecutive patients with pulmonary nodules (11 men, 10 women), who were referred to undergo thin-section CT scanning for the evaluation of pulmonary nodules. The CT images were acquired by a multi-detector row CT scanner (MDCT), it provides an image matrix size $512 \times 512$ pixels and a field-of-view of $200-250 \mathrm{~mm}$, and gives an in-plane resolution of $0.35-0.45 \mathrm{~mm}$. Twenty-one scan sets in the database comprise a total of 3400 images, with the number of images per set ranging from 60 to 250 , with a mean of 155 images per set.

\section{Results \& Discussion}

This CAD system can detect 60 nodules with two false positive nodules per case set and sensitivity $94.6 \%$ according to Table 1. The final diagnosis will be made by the radiologist (White CS, et al, 2007), while CAD systems may serve to flag probable nodules when the images are reviewed. 
With rapid advances in computers and $\mathrm{CT}$ image acquisition technology, $\mathrm{CAD}$ techniques will achieve improvements in diagnostic accuracy and move closer to the clinical arena. In the past decade, various CAD systems have been proposed for the detection of pulmonary nodules on CT images based on two-dimensional (2D) morphologic features on each section. In this study, the pulmonary nodules can be divided into three types in terms of their proximity to surrounding anatomic structures: isolated, juxtapleural, and vascular nodules. Detection of isolated nodules is easier than that of the other two types in terms of both human perception and computer detection, because the isolated nodules are surrounded by a distinctly low-attenuation pulmonary parenchyma. In contrast, detection of juxtapleural and vascular nodules is more challenging because these nodules may not be easily differentiated from abutting soft-tissue structures.

\section{Conclusion}

There is always the risk of missing a lesion as radiologists have to analyze large amounts of data per case with at least 400 cut per exam especially with new generation multi-detector row CT (MDCT), and 10-25 cases per day therefore, the proposed automated CAD system helps to avoid missing pulmonary nodule. It takes advantage of thin-section volumetric data of multi-detector row $\mathrm{CT}$ images to acquire complete a thoracic scanning within a single breath-hold. The system was organized to identify nodules of three different types (isolated, juxtapleural, and vascular) in terms of their locations or adjacent anatomic structures of non-nodule structures by 3D model. Calculating nodules 3D volumetric data set based on the determination of the features (volume, compactness, elongation) for the candidates then rule-based decision approach was used to flag nodules. Finally nodule candidates classified to malignant and non-malignant by using methods, such as those based on statistical methods like neural networks and estimate growth rate and doubling time for the nodule to state the malignancy level.

The results of this study demonstrated that a CAD system could detect pulmonary nodules, including small ones, with high sensitivity and a relatively low false-positive detection rate. Such a system may assist radiologists in the interpretation of CT images and mark the locations of suspicious objects for more attention, particularly, lung cancer screening as shown in Figure 6.

\section{References}

A. Materka \& M. Strzelecki. (1998). Texture analysis methods - a review. Technical University of Lodz, Institute of Electronics, COST B11 report.

Ahn MI, Gleeson TG, Chan IH, et al. (2010). Perifissural nodules seen at CT screening for lung cancer. Radiology, 254, 949-956. doi:10.1148/radiol.09090031, http://dx.doi.org/10.1148/radiol.09090031.

American Cancer Society. (2003). ACS cancer facts and figures 2002 (American Cancer Society, Atlanta, GA).

Armato SG, III, Giger ML \& MacMahon H. (2001). Automated detection of lung nodules in CT scans: preliminary results. Med Phys, 28, 1552-1561. doi:10.1118/1.1387272, http://dx.doi.org/10.1118/1.1387272.

Beigelman-Aubry C, Raffy P, Yang W, Castellino RA \& Grenier PA. (2007). Computer-aided detection of solid lung nodules on follow-up MDCT screening: evaluation of detection, tracking, and reading time. AJR, 189, 948-955. doi:10.2214/AJR.07.2302, http://dx.doi.org/10.2214/AJR.07.2302.

Binsheng Zhao, Gordon Gamsu, Michelle S. Ginsberg, Li Jiang \& wrence H. Schwartz. (2003). Matic detection of small lung nodules on CT utilizing a local density maximum algorithm. JOURNAL OF APPLIED CLINICAL MEDICAL PHYSICS, 4(3).

Brown MS, Goldin JG, Suh RD, McNitt-Gray MF, Sayre JW \& Aberle DR. (2003). Lung micronodules: automated method for detection at thin-section CT-initial experience. Radiology, 226, 256-262. doi:10.1148/radiol.2261011708, http://dx.doi.org/10.1148/radiol.2261011708.

C. H. Chen, L. F. Pau \& P. S. P. Wang. (1998). Handbook of Pattern Recognition and Computer Vision. ( $2^{\text {nd }}$ Edition). World Scientific Publishing Company.

Choi EJ, Jin GY, Han YM, Lee YS \& Kweon KS. (2008). Solitary pulmonary nodule on helical dynamic CT scans: analysis of the enhancement patterns using a computer-aided diagnosis (CAD) system. Korean J Radiol, 9 , 401-408. doi:10.3348/kjr.2008.9.5.401, http://dx.doi.org/10.3348/kjr.2008.9.5.401.

D. F. Yankelevitz, A. P. Reeves, W. J. Kostis, B. Zhao \& C. I. Henschke. (2000). Small pulmonary nodules: Volumetrically determined growth rates based on CT evaluation. Radiology, 217(1), 251-256. doi:10.1109/TMI.2003.817785, http://dx.doi.org/10.1109/TMI.2003.817785. 
D.-Y. Kim, J.-H. Kim, S.-M. Noh \& J.-W. Park. (2003). Pulmonary nodule detection using chest ct images. Acta Radiologica, (44), 252-257. [Online] Available: www.ncbi.nlm.nih.gov.

Fischbach F, Knollmann F, Griesshaber V, Freund T, Akkol E \& Felix R. (2003). Detection of pulmonary nodules by multislice computed tomography: improved detection rate with reduced slice thickness. Eur Radiol, 13, 2378-2383. doi:10.1007/s00330-003-1915-7, http://dx.doi.org/10.1007/s00330-003-1915-7.

Gurcan MN, Sahiner B, Petrick N, et al. (2002). Lung nodule detection on thoracic computed tomography images: preliminary evaluation of a computer-aided diagnosis system". Med Phys, 29, 2552-2558. doi:10.1118/1.1515762, http://dx.doi.org/10.1118/1.1515762.

H. Mller, N. Michoux, D. Bandon \& A. Geissbuhler. (2004). A review of content-based image retrieval systems in medical applications - clinical benefits and future directions. International Journal of Medical Informatics, 73, 1-23. doi:10.1016/j.ijmedinf.2003.11.024, http://dx.doi.org/10.1016/j.ijmedinf.2003.11.024.

Handbook of medical imaging: medical image processing and analysis. Bellingham, Wash: SPIE, 2000.

Henschke, CI, Yankelevitz, DF, Naidich, DP, McCauley, DI, et al. (2004). CT screening for lung cancer: suspiciousness of nodules according to size on baseline scans. 231(1):164-168. doi:10.1148/radiol.2311030634, http://dx.doi.org/1148/radiol.2311030634.

J. P. Ko \& M. Betke. (2001). Chest CT: Automated nodule detection and assessment of change over time-preliminary experience. Radiology, 218, 267-273.

Lee Y, Hara T, Fujita H, Itoh S \& Ishigaki T. (2001). Automated detection of pulmonary nodules in helical CT images based on an improved template-matching technique. IEEE Trans Med Imaging, 20, 595-604, doi:10.1109/42.932744, http://dx.doi.org/10.1109/42.932744.

Libby, DM, Smith, JP, Altorki, NK, Pasmantier, MW, et al. (2004). Managing the small pulmonary nodule discovered by CT. Chest, 125, 1522-1529. doi:10.1378/chest.125.4.1522, http://dx.doi.org/10.1378/chest.125.4.1522.

M. F. McNitt-Gray, E. M. Hart, N. Wyckoff, J. W. Sayre, J. G. Goldin \& D. R. Aberle. (1999). A pattern classification approach to characterizing solitary pulmonary nodules imaged on high resolution CT: Preliminary results. Med. Phys., 26(6), 880-888. doi:10.1118/1.598603, http://dx.doi.org/10.1118/1.598603.

M. F. McNitt-Gray, N.Wyckoff, J. G. Goldin, R. Suh, J.W. Sayre \& D.R. Aberle. (2001).Computer-aided diagnosis of the solitary pulmonary nodule imaged on CT: 2D, 3D, and contrast enhancement features. Proc. SPIE, 4322, 1845-1852. doi:10.1117/12.431075, http://dx.doi.org/10.1117/12.431075.

M. L. Giger, K. T. Bae \& H. MacMahon. (1994). Computerized detection of pulmonary nodules in computed tomography images. Invest. Radiol., 29(4), 459-465. doi:10.1097/00004424-199404000-00013, http://dx.doi.org/10.1097/00004424-199404000-00013.

M. S. Brown, M. F. McNitt-Gray, J. G. Goldin, R. D. Suh, J. W. Sayre \& D. R. Aberle. (2001). Patient-specific models for lung nodule detection and surveillance in CT images. IEEE Trans. Med. Imag., 20, 1242-1250. doi:10.1109/42.974919, http://dx.doi.org/10.1109/42.974919.

MacMahon H, Austin JH, Gamsu G, et al. (2005). Guidelines for management of small pulmonary nodules detected on CT scans: a statement from the Fleischner Society. Radiology, 237, 395-400. doi:10.1148/radiol.2372041887, http://dx.doi.org/10.1148/radiol.2372041887.

Michael Lam, Tim Disney, Mailan Pham, Daniela Raicu, Jacob Furst \& Ruchaneewan Susomboon. (2010). Content-Based Image Retrieval for Pulmonary Computed Tomography Nodule Images. doi:10.1117/12.710297, http://dx.doi.org/10.1117/12.710297.

Park EA, Goo JM, Lee JW, et al. (2009). Efficacy of computer-aided detection system and thin-slab maximum intensity projection technique in the detection of pulmonary nodules in patients with resected metastases. Invest Radiol, 44,105-113. doi:10.1097/RLI.0b013e318190fcfc, http://dx.doi.org/10.1097/RLI.0b013e318190fcfc.

Qian J, Fan L, Wei G, et al. (2002). Knowledge based automatic detection of multi-type lung nodules from multi-detector CT studies. Progress in biomedical optics and imaging, 3(2), 689-697. doi:10.1117/12.467211, http://dx.doi.org/10.1117/12.467211.

R. T. Greenlee, M. B. Hill-Harmon, T. Murray \& M. Thun. (2001). Cancer statistics, Cancer J. Clinicians, 51(1), 15-36. doi:10.3322/canjclin.51.1.15, http://dx.doi.org/10.3322/canjclin.51.1.15. 
Reeves AP \& Kostis WJ. (2000). Computer-aided diagnosis for lung cancer. Radiol Clin North Am, 38, 497-509. doi:10.1016/S0033-8389(05)70180-9, http://dx.doi.org/10.1016/S0033-8389(05)70180-9.

Reeves AP \& Kostis WJ. (2000). Computer-aided diagnosis of small pulmonary nodules. Semin Ultrasound CT, 21, 116-128. doi:10.1016/S0887-2171(00)90018-0, http://dx.doi.org/10.1016/S0887-2171(00)90018-0.

Russ JC. (2002).The image processing handbook. Boca Raton, Fla: CRC. doi:10.1201/9781420040760, http://dx.doi.org/10.1201/9781420040760.

S. Antani, L. R. Long \& G. R. Thoma. (2004). Content-based image retrieval for large biomedical image archives. In Proceedings of 11th World Congress on Medical Informatics (MEDINFO). [Online] Available: www.ncbi.nlm.nih.gov.

S. Toshioka, K. Kanazawa, N. Niki, H. Satoh, H. Ohmatsu, K. Eguchi \& N. Moriyama. (1997). Computer aided diagnosis system for lung cancer based on helical CT images. Proc. SPIE, 3034, 975-984. doi:10.1117/12.274186, http://dx.doi.org/10.1117/12.274186.

T. Andrysiak \& M. Choras. (2005). Image retrieval based on hierarchical gabor filters. International Journal Applied Computer Science, 15(4), 471-480.

Tao C, Gierada DS, Zhu F, et al. (2009). Automated matching of pulmonary nodules: evaluation in serial screening chest CT. American Journal of Roentgenology, 192, 624-628. doi:10.2214/AJR.08.1307, http://dx.doi.org/10.2214/AJR.08.1307.

Way TW, Hadjiiski LM, Sahiner B, et al. (2006). Computer-aided diagnosis of pulmonary nodules on CT scans: segmentation and classification using 3D active contours. Med Phys, 33, 2323-2337. doi:10.1118/1.2207129, http://dx.doi.org/10.1118/1.2207129.

White CS, Pugatch R, Koonce T, et al. (2008). Lung nodule CAD software as a second reader: a multicenter study. Acad Radiol, 15, 326-333. doi:10.1016/j.acra.2007.09.027, http://dx.doi.org/10.1016/j.acra.2007.09.027.

William J. Kostis, Anthony P. Reeves, David F. Yankelevitz \& Claudia I. Henschke. (2003). Three-Dimensional Segmentation and Growth-Rate Estimation of Small Pulmonary Nodules in Helical CT Images. IEEE TRANSACTIONS ON MEDICAL IMAGING, 22(10). doi:10.1109/TMI.2003.817785, http://dx.doi.org/10.1109/TMI.2003.817785.

Y. Matsuki, K. Nakamura, H. Watanabe, T. Aoki, H. Nakata, S. Katsuragawa \& K. Doi. (2002). Sefulness of an artificial neural network for differentiating benign from malignant pulmonary nodules on high-resolution ct. American Journal of Roentgenology, 657-663. [online] Available: http://www.ncbi.nlm.nih.gov.

Table 1. Values for volume, compactness and elongation features versus Diagnosis (Normal, Patient) and Classification (Benign, Malignant)

\begin{tabular}{|c|c|c|c|c|c|}
\hline & Wolume & Compactness & Elongation & Diagnosis & Classification \\
\hline 1 & 10.322 & ‥829 & 1.726 & 1 & $\square$ \\
\hline 2 & 13.BEE & ㅁ. & $1.31 \mathrm{gS}$ & 1 & $\square$ \\
\hline 3 & 4.511 & $\square .917$ & 1.3 .345 & 1 & $\square$ \\
\hline 4 & $13 \cdot 333$ & 1.695 & $1.4 \square 815$ & 1 & 1 \\
\hline 5 & 17.6 & 1.353 & 1.929 & 1 & 1 \\
\hline$E$ & 13.136 & 1.5427 & 1.685:3 & 1 & 1 \\
\hline 7 & B.1ET & 0.8475 & 1.333 & 1 & 1 \\
\hline$\theta$ & 12.25 & ㅁ. В00习 & 1. GBe日t & 1 & 1 \\
\hline 드 & 11 & ㅁ. 8145 & 2.0311 & 1 & 1 \\
\hline 10 & 14.95 & ㅁ.E1173 & $1 . E 747$ & 1 & $\square$ \\
\hline 11 & 15.33 & ㅁ. 4126 & 3.3948 & 1 & $\square$ \\
\hline 12 & E.5 & ㅁ.5909 & 2.2342 & 1 & $\square$ \\
\hline 13 & $7.11 \mathrm{GE}$ & ㅁ. 7545 & 1.7431 & 1 & $\square$ \\
\hline 14 & 915 & 口. ВПЗ & 1.552 & 1 & $\square$ \\
\hline 15 & 1 ㅁ. 19 & ㅁ.8B7ロ4 & 2.10ES7 & 1 & $\square$ \\
\hline $1 E$ & 51.5 & 4.023 & 2.452 & $\square$ & \\
\hline 17 & 52.5 & З.1므 & 2.283 & $\square$ & \\
\hline 18 & 84 & 3.733 & 1.628 & $\square$ & \\
\hline 19 & 74.6 & 3.5025 & 2. DBBB & $\square$ & \\
\hline 20 & 33.75 & 4.732 & 1.524 & $\square$ & \\
\hline 21 & 32.5 & $\exists .69 \exists$ & 1.945 & $\square$ & \\
\hline 22 & 45.75 & 4.017 & 1.552 & $\square$ & \\
\hline 23 & 32.143 & 3.905 & 1.599 & $\square$ & \\
\hline 24 & 46.125 & 4. DEB & 1.634 & $\square$ & \\
\hline
\end{tabular}




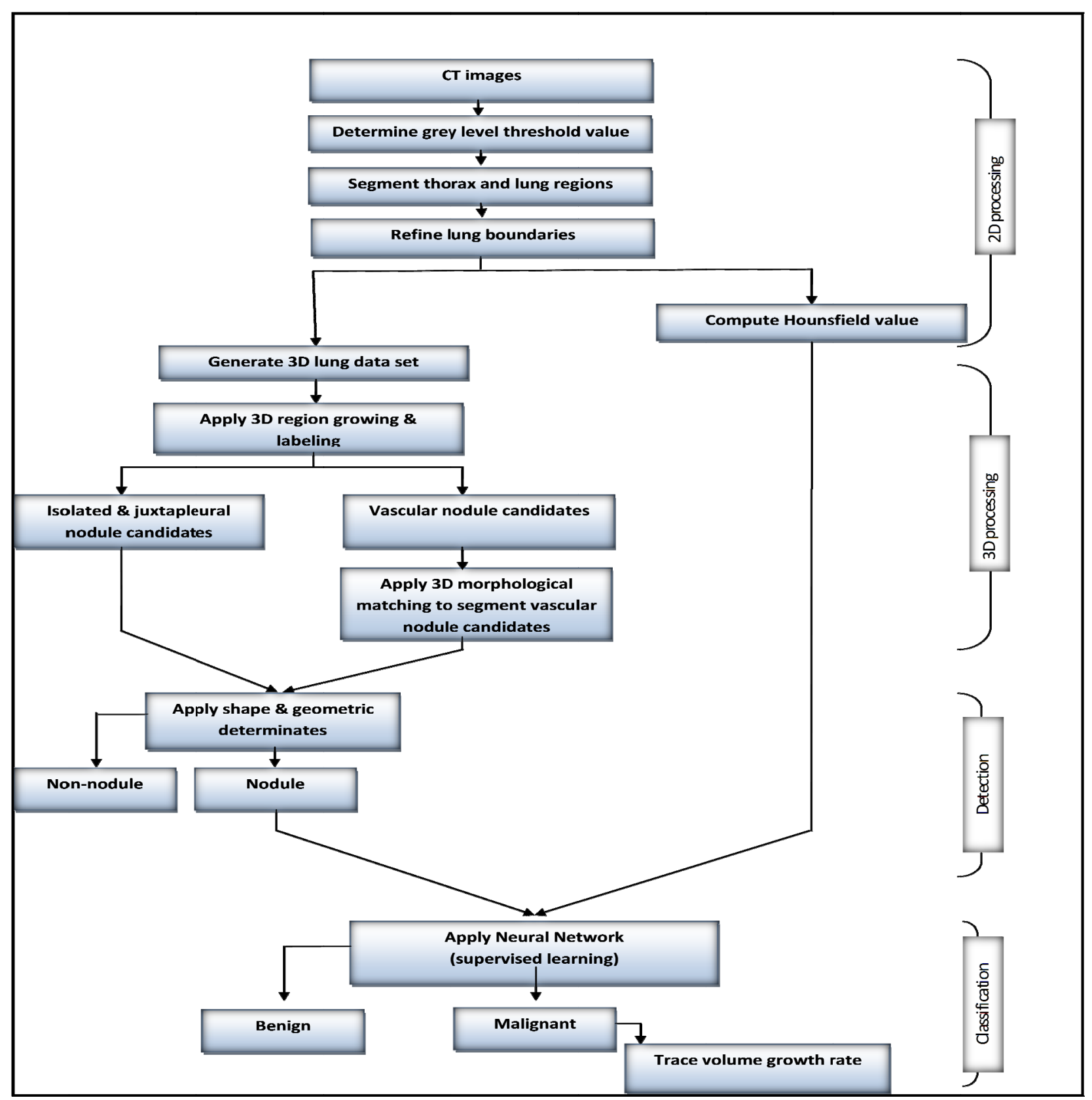

Figure 1. Flow diagram illustrates the overall scheme for automated lung nodule detection \& classification on CT images 


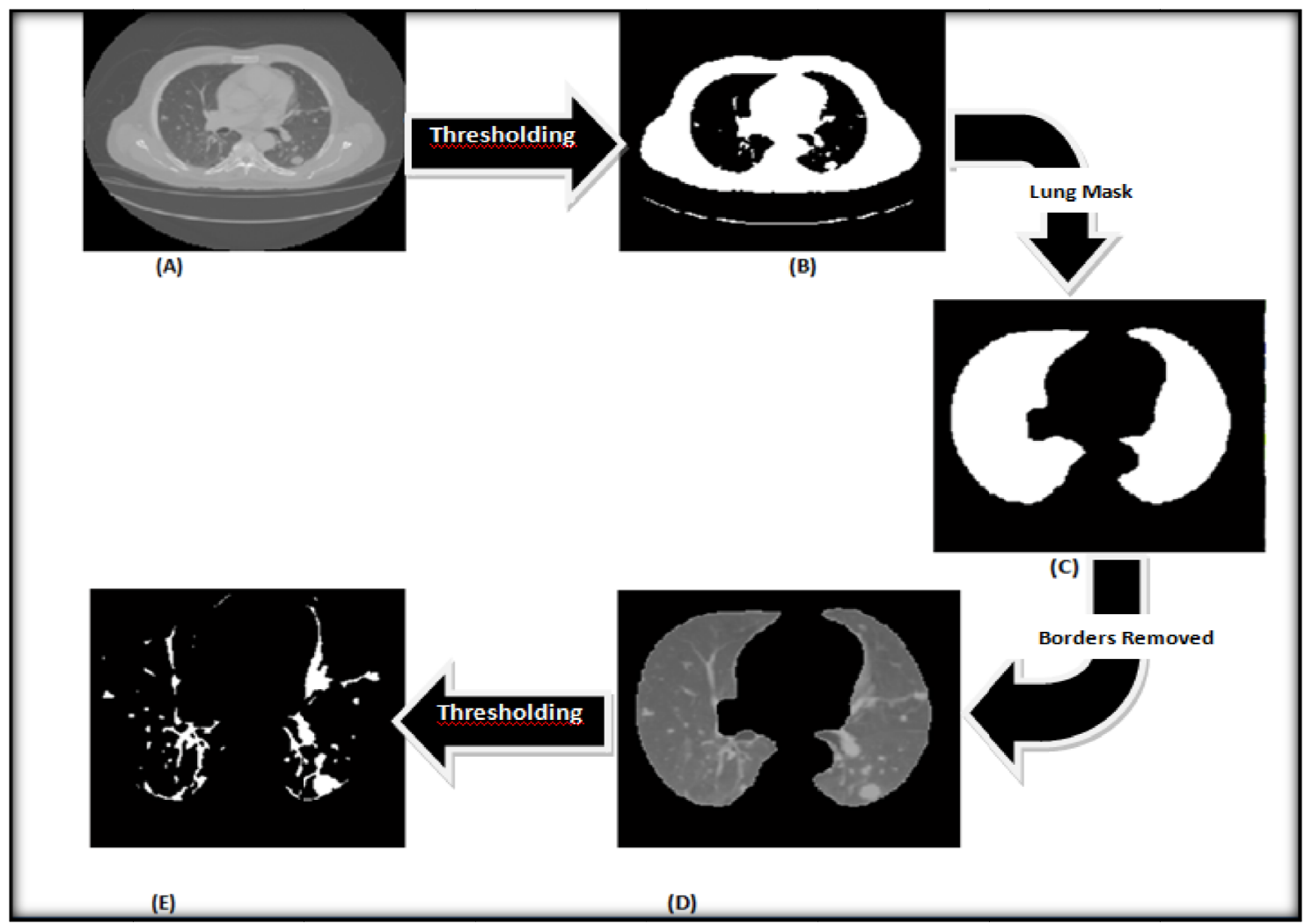

Figure 2. Intermediate 2D CT images illustrate the lung region segmentation process. (a) Transverse CT image of the thorax gray-level thresholding to generate. (b) a binary image. (c) Lung mask. (d) The initial CT image enclosed by this boundary was isolated. (e) The soft-tissue structures within the lung region were segmentation by means of gray-level thresholding

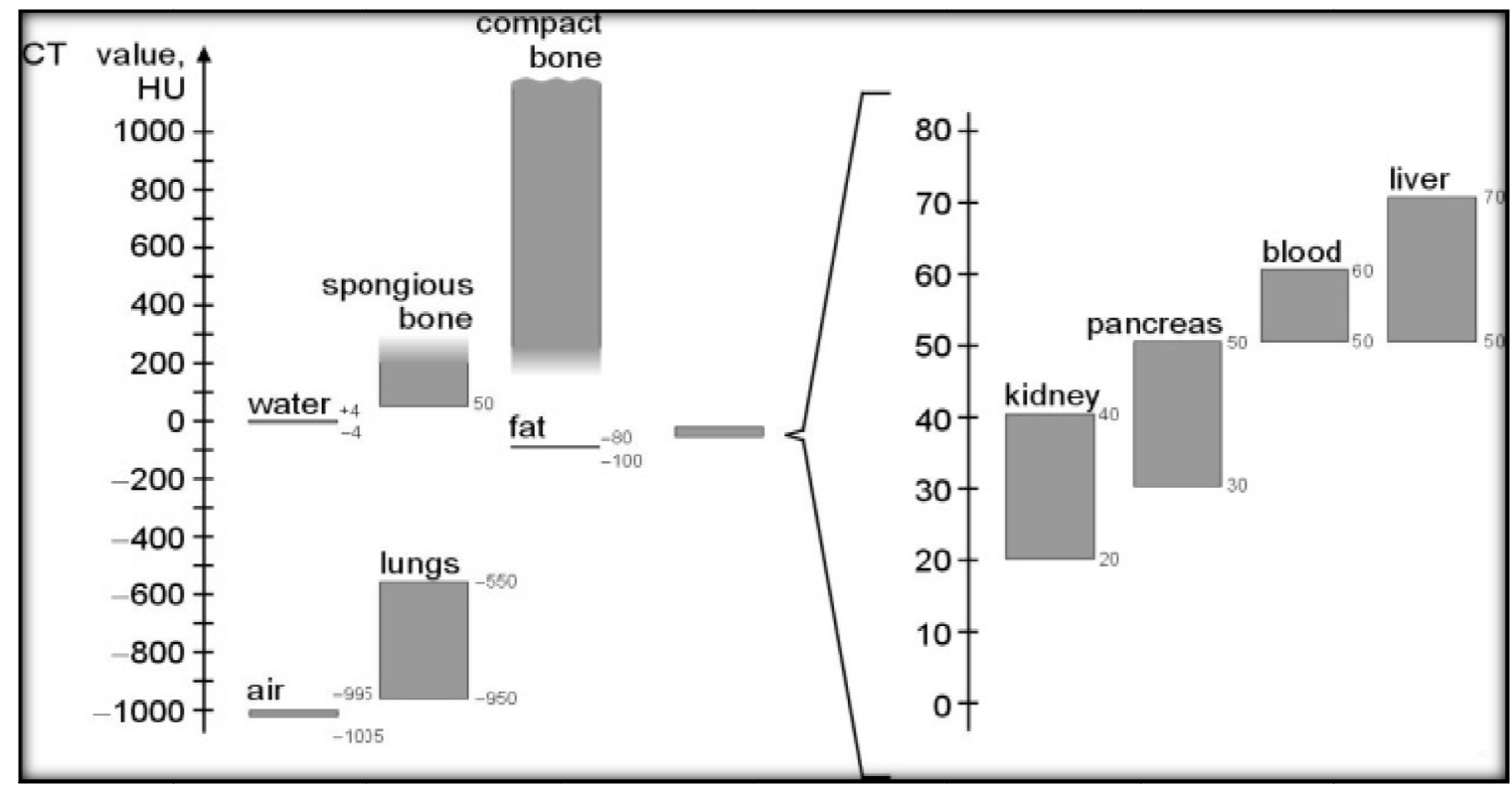

Figure 3. Hounsfield range values 


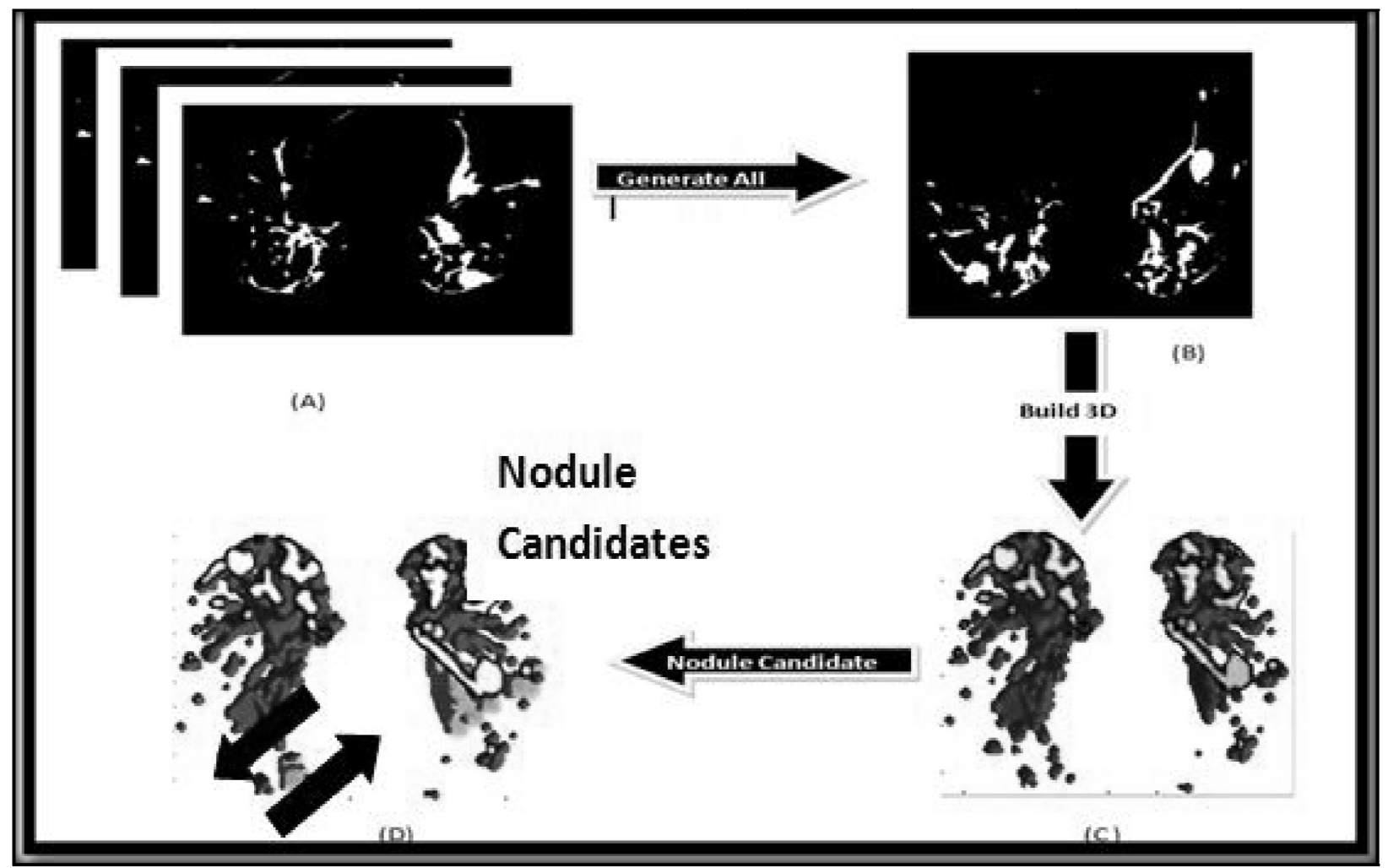

Figure 4. Segmented 3D volumetric data (a) group of images which in Figure 2e. (b) Image obtained by applying region growing and labeling to a stack $2 \mathrm{D}$ segmented lung images. (c) 3D data set of vessel group. (d) Image with nodule candidates 


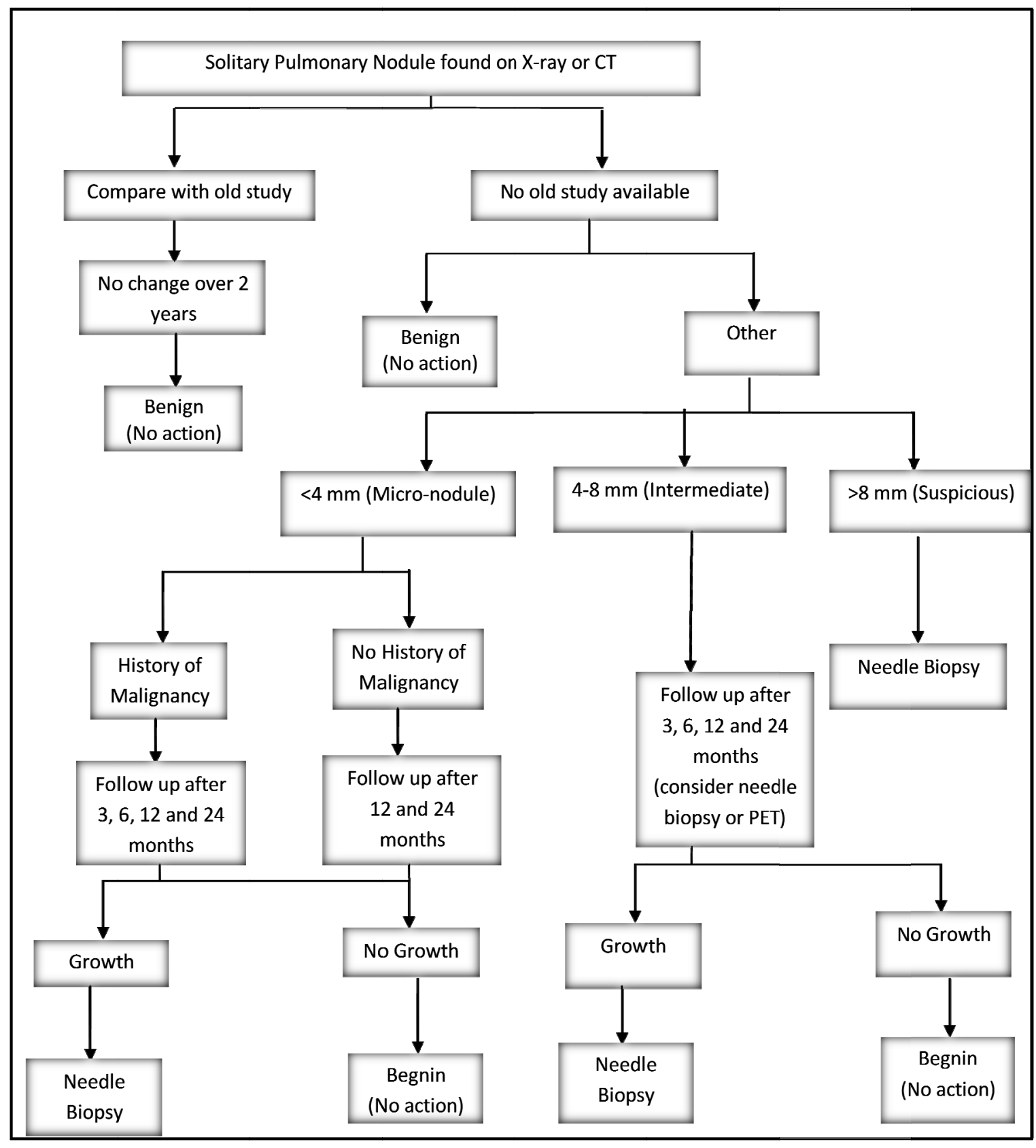

Figure 5. Evaluation of pulmonary nodules 


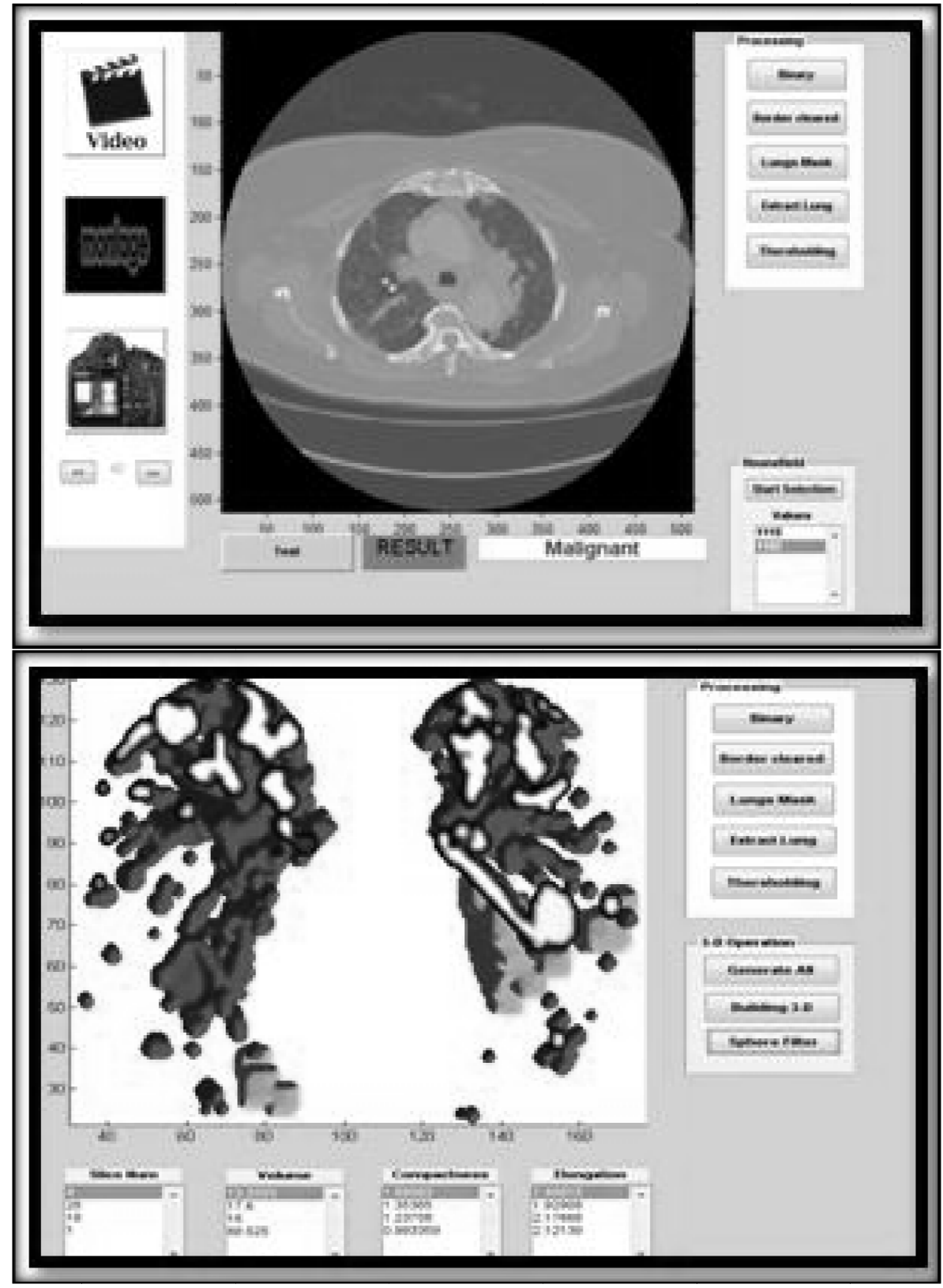

Figure 6. Screen Shots of our system in 2D and 3D operations on lung with detection of nodules (volume, compactness, elongation) and differentiating between malignant $\&$ benign ones 